\title{
A gestão ambiental no setor público: uma questão de relevância social e econômica
}

\author{
Environmental management in the public sector: \\ a question of social and economic relevancy
}

M artha M acedo de Lima Barata ${ }^{1}$

Débora Cynamon Kligerman ${ }^{2}$

Carlos M inayo-Gomez ${ }^{3}$

1Diretoria do Instituto Oswaldo Cruz, Comissão Interna deG estão Ambiental do IOC-CIGAmb,

Fundação O swaldo Cruz. Av. Brasil 4365 Pavilhão

Gomes de Faria 203,

Manguinhos. 21045-900

Rio deJaneiro RJ.

barata@ioc.fiocruz.br

${ }^{2}$ Fiocruz. Escola Nacional

deSaúdePública.

${ }^{3}$ Fiocruz. Escola $\mathrm{N}$ acional

deSaúdePública
Abstract Discussing the need to implement an environmental management system in civil service entities, this paper offers a brief description of some management practices used by companies in various sectors that are endeavoring to establish the best possible relationships between business activities, environmental issues and human needs, today and in the future. Some economic arguments are presented, including the benefits obtained by private sector companies adopting eco-efficiency criteria that are in themselves sufficient to justify the implementation of an effective environmental management policy in government institutions. The relevance is also stressed of drawing up the Civil Service Environment Agenda (A3P), striving to introduce a new cultural approach that will mobilize civil servants in order to optimize resources, combating wasteand encouraging better work environments. For this A genda to be effective, civil servants and managers must obviously be fully engaged.

Key words Environmental management, Civil service, Eco-efficiency
Resumo Este texto apresenta uma discussão a respei to da necessidade de implantar um sistema de gestão ambiental nos órgãos da administração pública. Efetua-se breve descrição de práticas gerenciais de empresas de setores variados que assumem o compromisso de estabelecer a melhor relação possível entre atividade empresarial, meio ambiente e necessidades humanas presentes e futuras. Expõem-se alguns argumentos de caráter econômico, referentes aos ben efícios obtidos por iniciativas privadas que adotaram critérios de ecoeficiência que, em si, seriam suficientes para justificar a implantação de uma política efetiva de gestão ambiental nas instituições públicas. D estaca-se a relevância da criação da Agenda Ambiental na Administração Pública $(A 3 P)$, que pretende instaurar uma nova cultura institucional, visando à mobilização dos servidores para a otimização dos recursos, para o combate ao desperdício e para a busca de uma melhor qualidade do ambiente de trabalho. Evidencia-se que para o êxito e efetivação da agenda será decisivo o grau de engajamento do próprio servidor e de seus dirigentes.

Palavras-chave Gestão ambiental, Administração pública, Ecoeficiência 
Introdução

Ao longo da década de 90 do século 20, foram implementados nas empresas instrumentos de gestão ambiental para o controle e a prevenção de danos ambientais, a fim de responder com maior eficiência às atuais demandas do mercado. Diversos instrumentos, desenvolvidos para melhorar seu desempenho ambiental, redundaram numa série de vantagens econômicas: redução de custos, aumento decompetitividade, abertura de novos mercados e diminuiçãa das chances de serem surpreendidas por algum tipo de ônusimprevisível eindesejável.

Tais argumentos de caráter econômico, por si só, já seriam suficientes para fundamentar a necessidade de que os órgãos da administração pública - e, mais ainda, os do setor de saúde assumissem o compromisso de velar pela conservação dos recursos naturais e a qualidade do meio ambiente. No entanto, instituições públicas que atuam no campo da pesquisa e da prestação de serviços biomédicos ainda carecem de uma política efetiva de gestão ambiental. M esmo executando serviços essenciais à sociedade, apresentam potencial poluidor capaz de causar danos à saúde de seus trabal hadores e à população localizada em seu entorno, além de contaminar o solo, a atmosfera, os rios e os lençóis freáticos.

Antecedentes históricos

da gestão ambiental corporativa

A constatação, ao final da década de 60 do século passado, de que a capacidade assimilativa dos ecossistemas e de regeneração dos recursos naturais ocorria a taxas incompatíveis com o desgaste imposto à natureza, contribuiu para reativar o questionamento clássico, em particular o malthusiano, acerca da compatibilidade no longo prazo entre o crescimento e a demografia, nos limites do patrimônio cultural fixo ${ }^{1}$. Em 1971, o Clube de Roma, por meio de modelos econométricos, previu o esgotamento dos recursos renováveis e não renováveis em face do modelo de crescimento, do padrão tecnológico e da estrutura da demanda. Seus resultados reativaram o debate acadêmico e político-institucional, conduzindo à aspiração ao desenvolvimento sustentável.

Nos primórdios, os setores produtivos limitavam-se, em alguns casos, a adotar as medidas necessárias para evitar a paralisação de suas atividades ou o recebimento de multas, por não atuar em conformidade com os procedimentose padrões legais. Entretanto, a ocorrência de acidentes ambientais - como o incidente na Allied Quemical Corporation, em Hopewell, Virgínia (EUA), em 1975; a explosão química da H offmanLa Roche, em Seveso (Itália), em 1976; 0 vazamento de gases tóxicos numa fábrica de pesticida da Union Carbideem Bhopal (Índia), em 1984; a explosão de reator nuclear em Chernobyl, na então União Soviética, em 1986; o vazamento de petróleo, em 1990, do navio petroleiro Exxon Valdez e o caso emblemático Love Canal, no estado de Nova York, um símbolo de contaminação do solo por resíduos sólidos enterrados obrigou as empresas a arcarem com elevados gastos em indenizações, recuperação dos ambientes danificados e ações para mitigação e/ou controle dos danos. Além disso, a imagem das empresas causadoras do dano foi afetada negativamente. Frente a esse quadro, empresas com maior potencial poluidor passaram a desenvolver e implementar instrumentos de gestão ambiental corporativa para a melhoria do fluxo de informação, interno e externo, além de propiciar a redução de risco de incidentes e acidentes.

O setor químico foi o pioneiro na elaboração de diretrizes para a gestão ambiental corporativa. A Canadian Chemical Producers Association (CCPA) lançou, em 1984, um documento denominado Statement of Responsible Care and Guiding Principles, contendo princípios específicos para a gestão responsável do processo de produção em todo o ciclo de vida do produto, dando ênfase à proteção da saúde humana e do meio ambiente e à segurança industrial e do produto. 0 documento, além de detalhar as iniciativas que as empresas precisam tomar para atender aos princípios do ResponsibleCare, destaca a necessidade de comprometimento de todos os envolvidos na produção, na distribuição e no recebimento dos produtos das respectivas empresas, assim como da troca permanente de informações com a comunidadevizinha. A adoção desses princípios em vários outros países, como EUA, Inglaterra e Brasil, contribuiu para resgatar uma imagem mais positiva da indústria química perante a opinião pública. Este tipo de ação coordenada, envolvendo grande número de empresas de um segmento industrial, seria, sob a ótica da gestão ambiental, um importante exemplo de estratégia cooperativa que, devido ao seu caráter pionei ro e a sua abrangência, viriam a ser seguidos, nos EUA, por diversos outros setores, em especial, pela indústria do petróleo.

Em face da crescente importância dadaà pro- 
teção ambiental ecom o objetivo de harmonizar globalmente os procedimentos de gestão ambiental empresarial, sem privilegiar determinados setores ou países, foram criados, em 1994, no âmbito da International Standard Organization (ISO), grupos detrabal ho para o desenvolvimento de normas, contendo diretrizes aplicáveis aos diferentes setores produtivos eregiões que possibilitem uma gestão e um produto com "qualidade ambiental". Em 1996, foram aprovadas e publicadas as normas ISO 14001 eISO 14004.

Na norma ISO 14001 - revisada e publicada nova versão, em 2000 - encontram-se especificados os requisitos gerenciais para estabelecer um Sistema de Gestão Ambiental (SGA) e obter a certificação, nos mais diversos tipos de organizações - respeitadas suas especificidades setoriais, geográficas, culturais e econômicas. $\mathrm{N}$ ela, estão sistematizados os procedimentos necessários para a definição dos princípios norteadores da política ambiental da empresa. Além de indicar - com base na política definida - a forma como serão planejadas eimplementadas as ações, fixam-se os prazos e os recursos necessários para sua operacionalização, assim como os meios para verificar a eficiência e eficácia do planejamento previsto e das ações implementadas, o que permite realizar - sempre que necessário - a correção de rumos para 0 atendimento aos princípios contidosna política. A norma também estabelece que a alta direção da organização deverá submeter-se periodicamente a revisões numa busca contínua de aperfeiçoar seu desempenho ambiental.

A certificação da empresa, pela norma ISO 14001, assegura a todas as partes interessadas (clientes, fornecedores, acionistas, força de trabalho, comunidade, governo e organizações não governamentais, dentreoutras) que as práticas gerenciais para a manutenção e melhoria do seu desempenho ambiental se ajustam ao estabelecido na norma, independente do setor e/ou local onde a empresa esteja atuando. Em outras palavras, este instrumento propicia a transparência ea unidade no fluxo de informações para o público interno e externo das empresas sobre os procedimentos de gestão ambiental aplicados por elas.

A relevância desteinstrumento podeser constatada pela quantidade e diversidade de empresas certificadas no mundo². Até2003, foram concedidas 36.765 certificações, das quais apenas 645 $(1,7 \%)$ correspondem a empresas situadas na América do Sul. A maior parte delas pertence a países de Europa (18.243) e Ásia (13.410), em cujas sociedades há um maior grau de preocu- pação ambiental etêm-se desenvolvido tecnologias menos poluentes. N o Brasil, até essa data, 0 número de certificações era de 570 , o que representa $88,37 \%$ do total das concedidas na América Latina. A média anual vem se mantendo em torno de 200, ao longo deste milênio, um número ainda relativamente pequeno, considerando o total de empresas em atividade no país, mas revelador de uma mudança significativa quando comparado com a situação anterior a 2001, em que as empresas certificadas eram apenas 120 .

Observa-se que entre as empresas certificadas apenas duas são do setor público, quatro se dedicam à preparação farmacêutica e à atenção médico-hospitalar e dez atuam na área de saúde e de serviços ${ }^{3}$. Esses dados são reveladores do pouco empenho de empresas do setor público sobretudo as que oferecem assistência médicohospitalar - em entrar num nível de gestão ambiental pautada por parâmetros garantidos e comparáveis internacionalmente. Uma explicação cabível desse desinteresse estaria na falta de evidência sobre as efetivas vantagens econômicas que a certificação proporcionaria às empresas de diferentes setores, tamanhos e localizações, considerando os custos do processo e dos procedimentos necessários para a aplicação da norma. Conseqüentemente, as empresas públicas só solicitariam a certificação quando impelidas por exigências do mercado ou de determinados atores sociais4.

O SGA, no entanto, contribui para a ecoeficiência das empresas, enquanto prática de produzir sempre bens e serviços mais úteis, concomitantemente à redução contínua do consumo de recursos e da poluiçãa $0^{5,6}$, o que traduz a preocupação em estabelecer a melhor relação possível entre atividade empresarial, meio ambiente enecessidades humanas presentes e futuras. Sob essa ótica, empresas de todos os tamanhos estariam aprimorando suas cadeias produtivas, incorporando ações que conduzem à melhoria do desempenho ambiental. Alguns desses avanços consistem na redução da obsolescência e da perda da manuten ção, reparo e operação (M RO) de materiais, através de práticas de gestão de estoques; decréscimo substancial de custos com sobras e perdas de materiais; aumento de receitas com a conversão de resíduos e desperdícios em subprodutos; redução do uso e do desperdício de solventes, pinturas e outras substâncias químicas, por meio de parcerias ou terceirização de serviços e reutilização de materiais, pela adoção de programas de retorno do produto. Atreladas ao sistema de gestão ambiental, inovações ope- 
racionais e tecnológicas são incorporadas ao longo do ciclo de vida de empresas que atuam em setores variados - química, el etroeletrônica, alumínio, automóveis, entre outros - com resultados positivos do ponto de vista econômico e ambiental 7,8 . Esses resultados raramente são percebidos, a não ser de forma muito pontual, pois as empresas carecem de mecanismos adequados para sua contabilização, razão pela qual consideram onerosos os gastos incorridos com a gestão e as certificação ambientais.

A gestão ambiental na administração pública

A criação da Agenda Ambiental na Administração Pública (A3P), no final de 1999, pelo M inistério do M eio Ambiente (MMA) e oficializada pela Portaria № 510/2002, vai ao encontro dos questionamentos expostos anteriormente sobre o número limitado de empresas do setor público certificadas pela ISO 14001. A Agenda pretende instaurar um processo de construção de uma nova cultura institucional na administração pública, visando à conscientização dos servidores para a otimização dos recursos para o combate ao desperdício e para a busca de uma melhor qualidade do ambiente de trabal ho ${ }^{9}$. V isa a colocar as empresas em sintonia com a concepção de ecoeficiência, incluindo critérios socioambientais nos investimentos, compras e contratações de serviços dos órgãos governamentais.

Em novembro de 2005, haviam aderido àA3P, entre outras instituições: a Presidência da República, o Ministério da Defesa, o Ministério de Minas e Energia, o Ministério da Educação, o M inistério da Saúde (Fundação N acional deSaúdee Agência N acional de Vigilância Sanitária), 0 M inistério de Desenvolvimento Social, a Secre taria do M eio Ambiente e Recursos Hídricos, a Procuradoria-Geral da República, o Supremo Tribunal Federal, o Superior Tribunal de Justiça, o Tribunal Superior Eleitoral, a Polícia Federal, o Tribunal de Contas da União, o Banco Regional de Desenvolvimento do Extremo Sul, diversas prefeituras municipais e o Serviço Brasileiro de Apoio às Micro e Pequenas Empresas.

Alguns dos procedimentos propostos são semelhantes aos da norma ISO 14001, não obstante, sua maior ênfase está na diminuição do desperdício, através dos $3 R$ 's, isto é: reduzir, reciclar e reutilizar a quantidade de resíduos gerados, sobretudo nos escritórios. Não são contempladas estratégias indicadas pela ISO 14001 como: levantamentos dos aspectos e impactos ambientais ao longo do ciclo de vida da produção ou dos serviços prestados e o estabelecimento de planos de emergência.

Para a implementação da A3P, o M M A propõe: a criação deum grupo responsável pela Agenda na empresa, composto por servidores de várias áreas da instituição; a realização do diagnóstico da situação, identificando pontos críticos e avaliando os impactos ambientais e desperdícios; a elaboração do planejamento integrado, envolvendo o maior número de colaboradores e áreas de trabalho; a definição de projetos e atividades, priorizando ações de maior urgência; a implementação das atividades programadas, re alizando treinamentos e disponibilizando recursos físicos e financeiros; a avaliação e o monitoramento do desempenho ambiental, identificando avanços e deficiências; a busca de uma melhoria progressiva através da avaliação sistemática, do replanejamento, da introdução de novas tecnologias e da capacitação de funcionários.

\section{O retorno econômico da implementação da gestão ambiental}

No Brasil, algumas metodologias, como a adotada pelo Programa de Produção M ais Limpa (PmaisL) e a desenvolvida por Barata ${ }^{8}$, vêm contribuindo para evidenciar os ganhos econômicos provenientes da gestão ambiental nas empresas. Tais metodologias apresentam o estudo da viabilidade econômica das ações necessárias para aprimorar o desempenho ambiental das empresas, contemplando a redução dos recursos naturais utilizados e da degradação ambiental.

O PmaisL foi implantado, em 1995, pelo Centro Nacional de Tecnologias Limpas do SENAIRS, através de convênio estabelecido com o Programa das Nações Unidas para o M eio Ambiente (UNEP) ea Organização das N ações Unidas para o Desenvolvimento Industrial (UNIDO). A metodologia do Programa propõeque inicialmente se realizem diagnósticos sobre os seguintes aspectos: 1) qualidade da gestão ambiental na empresa, avaliando sua adequação às exigências ambientais legais e de boas práticas de saúde ocupacional; 2) equipamentos edas técnicas existentes para o controle, a redução na fonte e o monitoramento de emissões (gasosas, líquidas e sólidas); 3) capacitação da força de trabalho, bem como das possíveis práticas existentes aplicáveis para a redução no uso de recursos (energia, água e matérias primas). Posteriormente, devem ser 
identificados os meios para solucionar as deficiências diagnosticadas e as oportunidades existentes para melhorar o desempenho ambiental da empresa, ponderando custos e benefícios financeiros decorrentes das ações oportunas da ecoeficiência.

Na primeira fase do Programa, a metodologia foi aplicada em onze pequenas e médias empresas que investiram um total de $R \$ 220$ mil e obtiveram ganhos financeiros da ordem de $\mathrm{R} \$$ $497 \mathrm{mil} / \mathrm{ano}$, em face da redução na geração de 97 ton/ano de resíduos perigosos, no consumo dematéria prima (120 ton/ano), deenergia (1660 $\mathrm{M}$ wh/ano) e de água ( $\left.120 \mathrm{mil} \mathrm{m}^{3} / \mathrm{ano}\right)^{10}$. As soluções propostas nem sempre envolveram investimentose, em muitos casos, representaram ape nas mudanças no processo operacional da empresa e treinamento dos funcionários.

Em virtude dos resultados iniciais apresentados, o Programa foi ampliado, constituindose numa Rede de Produção M ais Limpa, composta por entidades de apoio à indústria e ao comércio, instituições de ensino epesquisa eorganismos de financiamento, atuantes nos estados da Bahia, Ceará, M ato Grosso, Minas Gerais, Pernambuco, Santa Catarina, Rio de Janeiro e outros.

Na proposta de Barata ${ }^{8}$, a gestão ambiental permeia todos os setores e atividades da empre sa. 0 conjunto da força de trabal ho se torna responsável pelo desempenho ambiental na busca da ecoeficiência etambém na redução dos riscos financeiros provenientes de externalidades ambientais negativas inerentes às atividades desenvolvidas. Esta metodologia baseia-se na percepção de que, do ponto de vista gerencial, é fundamental estabelecer comparações entre investimentos necessários para controlar a degradação ambiental e custos potenciais da degradação provocada, a curto, médio e longo prazo, seja na recuperação ou mitigação dos impactos, seja na forma de indenizações ou compensações à sociedade pelos danos causados. São efetuadas estimativas de gastos com a implantação dos proce dimentose das tecnologias condizentes para atendimento aos padrões legais e normativos e dos possíveis custos e benefícios contingentes ou intangíveis.

Essa metodologia foi aplicada em três empresas localizadas no Estado do Rio de Janeiro, cujo porte, setor de atuação, faturamento e sistema de custeio utilizado eram distintos, mas tinham sido instaladas num período em que 0 conhecimento preciso dos danos que as atividades produtivas podiam ocasionar ao meio am- bienteera praticamenteinexistente. Concluiu-se que o custo de manutenção da gestão ambiental nas empresas não ultrapassa $2 \%$ de seu custo total. Entre os benefícios diretos destacam-se: a consultoria ambiental para outras unidades e empresas e a venda de equipamentos desenvolvidos para preservar, proteger erecuperar o meio ambiente. Quanto aos benefícios indiretos, sobressaem a redução de gastos propiciada pela maior eficiência no consumo de energia eágua e no volume de resíduos tratados.

Numa das empresas estudadas - que detinha um passivo ambiental elevado devido à prática de enterrar os resíduos - houve inclusive uma articulação para fornecer serviços e resíduos a terceiros que passaram a ser computados como receita direta. Essa mesma empresa empreen deu esforço técnico e financeiro para a implantação de estação de tratamento de resíduos industriais, evitando incorrer em gastos com medidas compensatórias que somavam, em 2000, o montante de $R \$ 1.500 .000,00$, além de multas e pagamentos de custas judiciais em decorrência do descarte de efluentes líquidos fora dos padrões da Licença de O peração. A implantação de uma gestão ambiental, portanto, pode - dependendo da atividade e de seu potencial gerador de passivo ambiental - evitar inclusive custos contingentes expressivos.

\section{Consideraçõesfinais}

As medidas adotadas para a redução dos impactos ambientais (presentes e futuros) - além de constituírem manifestações de responsabilidade social das empresas - podem redundar em retorno econômico. Para provar essa eficácia econômica, cabe ao responsável pela gestão ambiental ultrapassar a lógica de mera despoluição e investir no desenvolvimento de novos produtos geradores de receita; reduzir os custos de produção, utilizando menos insumos ou introduzindo mudanças tecnológicas; melhorar o relacionamento com clientes e demais partes interessadas ediminuir custos contingentes. Os métodos propostos subsidiam na definição de projetos ambientais a serem mantidos, implantados ou encerrados e de atividades a serem priorizadas, visando sempre a uma maior eficiência no desempenho ambiental eeconômico.

As empresas e instituições do setor público, particularmente as que têm como missão direta promover o bem-estar da sociedade, deveriam ser as primeiras a tomar a iniciativa de implantar 
um sistema eficiente de gestão ambiental. Aos fatores sociais associados à preservação ambiental e à saúde da população, somam-se os efeitos da melhor utilização de recursos públicos, pois a ecoeficiência se fundamenta na racionalidade das decisões, na análise de custo ebenefício das medidas a serem implementadas. Seria de desejar, portanto, que a A3P atue em conformi-

\section{Colaboradores}

M M L Barata, DC Kligerman e C M inayo-Gomez participaram igualmente de todas as etapas da elaboração do artigo.

\section{Referências}

1. Maimon D. Ensaios sobre economia do meio ambiente. Rio de Janeiro: APED; 1992.

2. International Organization for Standardization. [acessado 2003 Dez 29]. Disponível em: http:// www.iso.ch/isso/em/prods-services/otherspubs/ pdf/survey13thcycle.pdf

3. Instituto Nacional de M etrologia, N ormalização e Qualidade Industrial. [acessado 2005 Fev 28]. Disponível em: http://www.inmetro.gov.br

4. Barata M ML. Gestão ambiental empresarial. II Encontro Nacional da Sociedade Brasileira de Economia Ecológica: A economia ecológica e os instrumentos e políticas para uma sociedade sustentável. São Paulo; 1997.

5. Business Council for Sustainable Development. Internalizing Environmental Costs to Promote EcoEfficiency - Draft Task Force Report. Genebra, 1993.

6. Holliday C, Schimidheiny S, Watts P. Cumprindo o prometido: casos de sucesso de desenvolvimento sustentável. Rio de Janeiro: Campus; 2002. dade com os requisitos ambientais legais, evitando potenciais custos em compensação por danos ambientais. Para que as mudanças pretendidas por essa Agenda na cultura institucional possam efetivar-se, édecisivo o engajamento do próprio servidor e de seus dirigentes. Caso contrário, a Agenda será mais um programa governamental sem garantia de continuidade.
7. Environmental Protection Agency. The Lean and Green Supply Chain: A Practical Guide for M aterials $M$ anagers and Supply $C$ hain $M$ anagers to Reduce Costs and Improve Environmental Performance. EUA; 2000.

8. Barata M ML. Aplicação de uma estrutura contábil para apropriação dos custos ambientais e avaliação da sua influência no desempenho econômico das empresas [tese de doutorado]. Rio de Janeiro: COPPE/ UFRJ; 2001.

9. Ministério do M eio Ambiente. [acessado $2005 \mathrm{Dez}$ 07]. Disponível em: http://www.mma.gov.br

10. Centro Nacional de Tecnologias Limpas (CNTL). Resultados do Programa. Porto Alegre: CNTL/SENAI/UNIDO/UNEP; 1998.

Artigo apresentado em 20/01/2006

Aprovado em 16/06/2006

Versão final apresentada em 31/08/2006 